\title{
Influence of Fiber Reinforcement on the Properties of Denture Base Resins
}

\author{
Rama Krishna Alla ${ }^{1 *}$, Suresh Sajjan ${ }^{2}$, Venkata Ramaraju Alluri ${ }^{2}$, Kishore Ginjupalli $^{3}$, Nagaraj Upadhya ${ }^{3}$ \\ ${ }^{1}$ Department of Dental Materials, Vishnu Dental College, Bhimavaram, India; ${ }^{2}$ Department of Prosthodontics \& Implontology, \\ Vishnu Dental College, Bhimavaram, India; ${ }^{3}$ Department of Dental Materials, Manipal College of Dental Sciences, Manipal, India \\ Email: *ramakrishna.alla@lycos.com
}

Received October $9^{\text {th }}, 2012$; revised November $15^{\text {th }}, 2012$; accepted December $16^{\text {th }}, 2012$

\begin{abstract}
Advances in the medical sciences along with rapid increase in the specialized and better treatment modalities, certainly prolonged the human life with a drastic increase in the number of elderly in the past few decades. Tooth loss is one of the manifestations of aging. Dentures and dental implants are the major prosthetic devices given to restore physiological and esthetic functions of oral tissues of edentulous or partially edentulous patients. Complete and partial dentures based on polymeric compositions are the most popular devices since the cost of dental implants and metal-base dentures are much higher. Among the polymers, poly (methyl methacrylate) (PMMA) is the most commonly used material for this purpose. Although, this material is not ideal in every respect, it is the combination of qualities rather than one single desirable property that accounts for its popularity and usage. One of the main drawbacks of this material is considered to be its poor mechanical performance. There have been several attempts in the recent past to address the problem of inferior mechanical properties of these materials. Generally, there are three ways which have been investigated to improve the mechanical properties of denture bases; search for or development of an alternative material to PMMA; chemical modification of PMMA; and the reinforcement of PMMA. Present article is a review of types of fibres reinforced in denture prosthesis and their effects on mechanical properties of denture prosthesis.
\end{abstract}

Keywords: Poly (Methyl Methacrylate); Metallic Fillers; Fibres; Elastic Modulus; Impact Strength; Fracture

\section{Introduction}

The science of biomaterials rapidly evolved over the last few decades largely contributing to the increase in the life expectancy of human beings. Research in dental materials involved modification of existing materials or development of new and better materials for prosthetic and restorative applications. The goal of research has been to replace or restore lost or damaged tooth structure satisfying esthetic and functional requirements. Although, dental implants have received large attention with a high success rate for the treatment of complete and partially edentulous conditions, dentures remain the most popular choice of prosthetic devices. Dentures made from resin based polymeric systems were popular because of their ability to be molded with ease with excellent esthetic appearance and suitable mechanical characteristics in most clinical conditions. An ideal denture base material is the one that possesses biocompatibility with the oral tissues, excellent esthetics, superior mechanical properties especially modulus of elasticity, impact strength, flexural strength and hardness, sufficient bond strength

${ }^{*}$ Corresponding author. with artificial teeth and lining materials, ability to repair or alter the contours and dimensional accuracy [1].

\section{History}

History of complete dentures for the treatment of edentulism dates back to $700 \mathrm{BC}$. Since then several materials such as bone, wood, ivory, and vulcanized rubbers were utilized to fabricate complete dentures. During the early 1900 's poly vinyl chloride, vinyl acetate, modifications of bakelite and cellulose plastics were used [1,2]. However, it was in 1937, "Walter Wright" introduced Poly (methyl methacrylate) [PMMA] material as denture base material and it was found to be the most superior material over all other denture base materials. It became so popular that during 1940s' almost all the dentures were fabricated with acrylic based materials [3]. Although, several new materials such as polystyrene and light-activated urethane dimethacrylate were introduced, PMMA remained the most preferred material of choice for both complete and partial denture prostheses.

The popularity of PMMA as denture base material was attributed to its ease of processing, low cost, lightweight, 
excellent aesthetic properties [4-6], low water sorption and solubility; and ability to be repaired easily. However, low thermal conductivity, inferior mechanical strength, brittleness, high coefficient of thermal expansion and relatively low modulus of elasticity makes it more prone to failure during the clinical service $[1,2,5]$.

\section{Reasons for Failure of Denture Prosthesis Made from PMMA}

Clinical failure of complete or partial denture prosthesis made from PMMA are most likely in the form of fracture either due to fatigue [7] or impact forces of mastication [8]. Flexural fatigue of dentures as evidenced by midline fracture is due to the stress concentration around the micro cracks formed in the material due to continuous applications of small forces. Repeatative nature of masticatory load results in propagation of cracks which weakens the denture base and finally results in fracture [1,9-11]. Fracture of dentures by impact forces, on the other hand, results from the sudden application of force to the dentures. Such types of fractures are more likely due to the accidental dropping of dentures on surfaces during cleaning of dentures by patients [1].

Fracture of dentures in clinical service has been a concern and several attempts have been made to improve flexural and impact strength of PMMA. Research in this area aimed at modifying the composition or reinforcing the PMMA with stronger materials and developing new materials with better properties [12].

\section{Chemical Modification of PMMA and Alternative Polymers to PMMA}

Attempts to modify the composition of PMMA material led to the development of high impact strength acrylic denture bases. It is a graft copolymer of butadiene styrene rubber with PMMA $[3,13]$. However, these materials showed poor flexural strength compared to conventional acrylic resins [14]. Although, various materials based on polyamides, epoxy resins, polystyrene, vinyl acrylics, light-activated urethane dimethacrylate, rubber graft copolymers and polycarbonate [14] and nylon [15] have been introduced to overcome the mechanical deficiencies of PMMA, these materials were not as good as PMMA.

\section{Reinforcement of PMMA Denture Bases}

\subsection{Metallic Fillers}

Reinforcement of acrylic denture base materials to improve the mechanical strength has been the focus of research for some time [1] Reinforcing agents in the form of cobalt-chromium wires [3], metallic wires [16], varying amounts of powdered silver, copper, aluminium [17] and ceramic fillers [18] have been added to PMMA matrix with considerable improvement in the compressive strength [17]. The purpose of adding powders of silver, copper and/or aluminium is to improve the thermal conductivity and to decrease the curing shrinkage and water sorption [17]. However, such additions were not successful due to the lack of interfacial bonding between the metallic fillers and the resin matrix. Attempts such as sand blasting of the metal surface and use of metal primers have been reported to achieve interfacial bonding between the metal and the resin [19].

\subsection{Fibers}

Rapid and fast changing concepts of composite technology led to the reinforcement of materials using fibres $[3,20,21]$. Several types of fibres including carbon fibres, glass fibres and ultra-high modulus polyethylene fibers have been employed to reinforce PMMA resin [22]. Considerable research has been carried out in this area with an improvement in the mechanical characteristics. However, the ability of fibres to reinforce the denture base was found to be dependent on the individual properties of the fibres and resin matrix; impregnation of fibres with resin; adhesion of fibres to the matrix; volume of fibres in the composite matrix; orientation of the fibres and location of fibres in the prosthesis [20,23,24].

\subsubsection{Nylon Fibres}

These are polyamide fibres and are based primarily on aliphatic chains. The chief advantage of nylon lies in its resistance to shock and repeated stressing. However, water absorption affects the mechanical properties of nylon. Nylon-reinforced denture bases display higher fracture resistance than PMMA [25].

\subsubsection{Carbon Fibers}

Use of carbon fibres to improve the strength of denture bases was reported by Larson et al. 1991. The bulk of carbon fibres were made by heating polyacrylonitrile in air at $200^{\circ} \mathrm{C}-250^{\circ} \mathrm{C}$ followed by heating in an inert atmosphere at $1200^{\circ} \mathrm{C}$, that removes hydrogen, nitrogen and oxygen, leaving a chain of carbon atoms and thus forming carbon fibres $[12,26]$.

Carbon fibers were mainly used to improve fatigue behaviour and impact strength. It is difficult to handle the dry carbon fibres and must be wetted with monomer to form the tows of wet fibre [12]. The tows of wet fibre can be laid side by side and enclosed in a thin sheet of PMMA to form a prepeg, which can significantly increase the transverse strength and reduce the fracture of dentures compared to unreinforced acrylic resins $[12,27]$. However, fibres must be coated with a silane coupling agent to provide proper adhesion between fibres and PMMA resin. 
The different orientations of carbon fibres include strand form, woven mat form, layered fibres, random, longitudinal and perpendicular to the applied force. Resins which contain layered fibres of specific orientation exhibit increased resistance to applied stress and significantly increase the flexural fatigue resistance of fibre reinforced acrylics [12]. Isa et al. (2011) [28] studied and compared the flexural properties of denture bases reinforced with carbon, aramid and glass fibers, which were arranged in long axis of the specimen and it was found to be the flexural strength of denture base polymers reinforced with carbon fibres were more than the other fibers studied [28]. Uzun et al. (1999) observed a significant improvement in the impact strength and elastic modulus of acrylic denture base reinforced with woven carbon fibres [3]. It was also observed that strand form of carbon fibre reinforcement has the superior transverse strength than woven mat form $[12,26]$. Longitudinally oriented fibres increase the flexural fatigue resistance than the random fibre arrangement. Carbon fiber orientation perpendicular to the direction of the applied stress produced the most favourable combination of increased resistance to bending and to flexural fatigue. Impact strength of carbon fibre reinforced acrylic denture base resin can be increased by increasing the fibre length and concentration in the polymeric matrix [29].

Biological evaluation of carbon reinforced denture base materials has not been evaluated extensively although cytotoxicity of carbon fibers is considered to be a problem. There is a possibility of skin irritation on handling carbon reinforced denture base specimens [12,26,30]. Ekstrand et al. (1987) assessed the cytotoxicity of leachable elements from carbon-graphite fibres subjected to different surface treatments using agar overlay technique and found that fibers with cleaned surfaces were less cytotoxic than the non-treated ones [31].

Carbon fibres are not so extensively used currently because of their difficult handling techniques, problems with polishing $[12,32,33]$, poor esthetics due to black color of the fibres $[12,29,33]$ and potential toxicity [12, 26,30].

\subsubsection{Aramid Fibres}

The commercial name for aramid fibre is Kevlar and chemically it is an organic compound such as polyparaphenylene terephthalamide with chemical formula (-CO- $\left.\mathrm{C}_{6} \mathrm{H}_{4}-\mathrm{CO}-\mathrm{NH}-\mathrm{C}_{6} \mathrm{H}_{4}-\mathrm{NH}-\right)_{\mathrm{n}}[12]$.

Kevlar fibres are popular as they exhibit superior mechanical properties than nylon and E-glass fibres. Polyaramid fibres have superior wettability compared to carbon fibres and do not require treatment with a coupling agent. The incidence of flaw at the site of reinforcement in denture base was found to be less with Kevlar fibers. They were found to improve both tensile strength and modulus of elasticity of denture bases. Acrylic resin appliances reinforced with fibre content up to $2 \%$ and with unidirectional orientation showed significantly higher impact strength and fatigue resistance [34]. Hardness of the aramid fibre reinforced denturebase resin can be decreased by increase in fibre concentration [29]. Further, aramid fiber reinforced denture was found to be biocompatible with no evidence of toxicity [29].

These fibres are not extensively used now because of their yellow hue $[12,29]$ and exposed fibres at the surface of the resin results in rough surface which makes it difficult to polish. Poor adhesion between fibres and acrylic resin has also been reported in the literature [35]. However, these fibres are widely used for the fabrication of bullet-proof vests, automobile tyres, boat hulls and aircrafts [12].

\subsubsection{Ultra-High Molecular Weight Polyethylene} Polyethylene fibers were claimed to enhance the physical properties of acrylic resin. They are added to PMMA resin to produce denture bases with enhanced modulus in the axial direction. They exhibit many favourable properties for use as reinforcing agent in denture bases such as high ductility, neutral colour, low density and superior biocompatibility. They can be drawn as monofilament fibres and woven into fabrics. The adhesion between the fibres and PMMA resin can be promoted by an electrical plasma treatment, which etches the surface of fibres into which the resin gets impregnated so that they bond mechanically to the resin phase [36].

Concentration, orientation and length of the fibres greatly influence the mechanical properties of Ultra-high molecular weight polyethylene reinforced PMMA resins. Fibre concentration less than 3\% that are treated with electrical plasma treatment were found to significantly improve the strength $[37,38]$. Further, it was also observed that concentrations as low as $1 \%$ can significantly improve impact strength. However, greater than $3 \%$ of these fibres in PMMA resin makes the dough unworkable. Uzun et al. (1999) reported that the woven polyethylene fibre reinforcement can significantly increase the impact strength and elastic modulus [3]. The process of etching, preparing, and positioning layers of woven fibres, however, may be impractical for the dental laboratory practice $[3]$.

\subsubsection{Glass Fibres}

Inherent drawbacks of carbon and aramid fibres such as difficulty in polishing, unesthetic appearance [32] and complicated surface treatment procedure of polyethylene fibres demanded an alternative material for the reinforcement of dentures [36,39]. Main reasons for much attention towards the glass fibre reinforcement is due to their excellent aesthetic appearance [22,40], superior 
mechanical properties $[3,40]$ and biological compatibility $[9,40,41]$.

Glass fibres have been used in different forms to strengthen dental polymers, including continuous fibres similar to a woven sheet, loose stick, stick net forms [42$44]$ and short-rod glass fibres [21,29,45-47]. Glass fibers are not very resistant to impact forces but their strength can be improved by using many unidirectional glass fibers (stick) or by using woven glass fiber (stick net) [40]. Continuous fibres have been widely investigated as they provide high strength and modulus in a direction parallel to the fibres [48]. However, they are difficult to construct and it is difficult to orientate the continuous fibres at weak regions of denture base during fabrication process [47]. Short-rod glass fibre reinforcement also was found to provide similar reinforcement effect and is used easily with conventional compression molding techniques [47]. Stick fiber reinforcement has superior flexural modulus and transverse strength than the stick net fibre reinforcement $[48,49]$.

As the mechanical properties of glass fibre reinforced PMMA depends on the strong adhesion between glass fibres and acrylic resin matrix, glass fibres are generally treated with silane coupling agent before loading into the acrylic resin matrix. Several investigations have concluded that silane treated fibre reinforced acrylics have higher transverse strength and fracture resistance than untreated glass fibre reinforced acrylics [16,21,29,42, 50,51]. On contrary, Kanie et al. [32] did not find significant differences in flexural strength between the treated and untreated materials. Uzun et al. (1999) and Hari Prasad et al. (2011) reported that the woven glass fibre reinforcement can significantly increase the impact strength [3,51]. Vojdani et al. (2006) [16] reported that the transverse strength is greater when glass fibers are reinforced in unidirectional than the woven arrangement. On contrary, Unalan et al. (2010) [52] reported that the transverse strength is more with woven fiber reinforcement than the unidirectional glass fiber reinforcement. VojVodic et al. (2009) [53] compared the properties of reinforced dentures with dental grade (silanized glass fibers) and industrial grade (non-silinized glass fibers) glass fibers. It was concluded that the industrial glass fibers provided better flexural strength and also are inexpensive than dental grade glass fibers.

The position and concentration of glass fibres and short-rod glass fibre reinforcements within the polymer greatly affects the strength. Placing the fibres normal to the loading force can improve the strength [52,54]. Goguta et al. (2006) [40] reported that PMMA reinforced with glass fibres (stick net and stick) significantly improved impact strength. Stick reinforcement significantly increased the impact strength when fibers are placed parallel to the long axis of the specimen and perpendicularly to the impact force direction. Isa et al. (2011) [28] observed less flexural strength with glass fibres compared to carbon and aramid fibres reinforced along the long axis of the specimens. Quantity of fibre reinforcement influences the flexural and impact strength of denture base polymers. It was found that less is the quantity of fibre reinforcement greater will be the flexural and impact strength [32]. Greater than $20 \%$ of fibre reinforcement has effects on doughing properties. Further, inhomogenous distribution of fibers in the matrix may be resulted during pressing the mold that leads to the uneven lateral spreading of fibres in the polymer matrix [12]. Stipho (1998) reported that PMMA resins reinforced with $1 \%$ of short-rod glass fibres provided the better flexural strength than the resins reinforced with more than $5 \%$ of short-rod glass fibres. This is due to the tendency of fibres to clump together when mixed with a polymer and results in porosity due to the formation of void spaces in the resin matrix [21]. Use of injectionmolding processing technique and fine acrylic powder particles can reduce the void formation therefore increase the flexural strength significantly [46]. Nakamura et al. (2007) [47] reported that using smaller PMMA powder particles reinforced with more concentration of short-rod glass fibres.

Poor wetting of fibres within the acrylic resin and polymerization shrinkage of acrylic dough reduces the bond strength of fibres leading to the formation of voids inside the resin matrix [43]. Polymerization shrinkage can be minimized by the pre-treatment of fibre with a PMMAmethyl methacrylate (MMA) mixture [3]. But using excess amount of MMA monomer would increase the polymerization shrinkage which results in dimensional changes within the denture. Further, such a process may also allow more amount of residual monomer to release from the glass fibre reinforced acrylic dentures which may lead to biocompatibility concerns [55-57].

Vallittu (1997) proposed total fibre reinforcement (TFR) and partial fibre reinforcement (PFR) concepts for reinforcing denture bases using fibres [58]. TFR involves dispersion of reinforcing agent throughout the matrix material uniformly whereas PFR generally involves placement of reinforcing agent at the weakest portion of prosthesis. It was shown that a significant improvement in mechanical properties of complete and partial dentures can be achieved with unidirectional PFR using electrical glass (E-glass) fibers [59]. The highest strength for fibre composite can be obtained with fibres oriented in one direction. TFR are available in a weave [3] or mat form which are multidirectional and exhibit less strength than PFR which are unidirectional. One of the main problems encountered with multidirectional fibres is that they may be protruded from the denture surface and cause tissue irritation [58]. 
Ozen et al. (2006) [30] assessed the cytotoxicity of conventional and reinforced heat cure acrylic resins and observed that the reinforced acrylics are more cytotoxic compared to conventional acrylics.

A new kind of fibre reinforcement system was developed by Vallittu \& Narva (1997). This system employs a combination of two different fibres such as glass fibres and aramid fibres which are then embedded in a resin matrix [60]. One advantage of such a combination is that the glass fibre reinforcement does not negatively effect the water sorption and solubility properties of PMMA resin [61].

\subsubsection{Jute Fibers}

Kondo et al. (2009) [62] reinforced the dentures with chopped jute fibres to improve bending strength. No significant improvement in flexural properties was observed and they suggested further studies on surface treatment and aspect ratio of jute fiber.

\section{Conclusion}

Poly (methyl methacrylate) will continue to be the preferred material of choice for the fabrication of complete and partial denture prostheses. Attempts to improve the strength characteristics of the material would result in prolonging the service life of acrylic dentures. Reinforcement of dentures with various fibres have shown a significant improvement in flexural strength, impact strength and fatigue resistance of the materials. However, significant difference in reinforcing characteristics of different fibres was evident from the literature. Further, processing of fibre reinforced denture bases seems to be technique sensitive and difficult to fabricate in the dental laboratory. Although, improved mechanical properties make fibre reinforcement of dentures attractive, further research needed to address the biological effects of these reinforced materials.

\section{REFERENCES}

[1] T. R. Meng and M. A. Latta., "Physical Properties of Four Acrylic Denture Base Resins," Journal of Contemporary Dental Practice, Vol. 6, No. 4, 2005, pp. 93-100.

[2] R. W. Phillips, "Skinner's Science of Dental Materials," 10th Edition, W.B. Saunders, Philadelphia, 1996, pp. 237-300.

[3] G. Uzun, N. Hersek and T. Tinçer, "Effect of Five Woven Fiber Reinforcements on the Impact and Transverse Strength of a Denture Base Resin," Journal of Prosthetic Dentistry, Vol. 81, No. 5, 1999, pp. 616-620. doi:10.1016/S0022-3913(99)70218-0

[4] M. Vojdani, M. Sattari, Sh. Khajehoseini and M. Farzin, "Cytotoxicity of Resin-Based Cleansers: An in Vitro Study," Iranian Red Crescent Medical Journal, Vol. 12, No. 2, 2010, pp. 158-162.
[5] R. G. Craig and J. M. Power, "Restorative Dental Materials," 11 th Edition, Mosby, St. Louis, 2002, pp. 87-99.

[6] M. H. El-Mahdy, W. E. El-Gheriani, B. A. Idris and A.-H. A. Saad, "Effect of Coupling Agents on the Important Physico-Mechanical Properties of Acrylic Resin Reinforced with Ceramic Filler," Ainshams Dental Journal, Vol. 8, No. 2, 2005, pp. 243-254.

[7] U. R. Drabar, R. Huggett and A. Harrison, "Denture Fracture-A Survey," British Dental Journal, Vol. 176, 1994, pp. 342-345. doi:10.1038/sj.bdj.4808449

[8] A. Arikan, Y. K. Ozkan, T. Arda and B. Akalın, "Effect of 180 Days of Water Storage on the Transverse Strength of Acetal Resin Denture Base Material," Journal of Prosthodontics, Vol. 19, No. 1, 2010, pp. 47-51. doi:10.1111/j.1532-849X.2009.00495.X

[9] Y. Hirajima, H. Takahashi and S. Minakuchi, "Influence of a Denture Strengthener on the Deformation of Complete Denture," Dental Materials Journal, Vol. 28, No. 4, 2009, pp. 507-512. doi:10.4012/dmj.28.507

[10] P. K. Vallittu, "Fracture Surface Characteristics of Damaged Acrylic-Resin-Based Dentures as Analysed by SEMReplica Technique," Journal of Oral Rehabilitation, Vol. 23, No. 8, 1996, pp. 524-529. doi:10.1111/j.1365-2842.1996.tb00890.x

[11] H. W. A.Wiskott, J. I. Nicholls and U. C. Belser, "Stress Fatigue: Basic Principles and Prosthodontic Implications," International Journal of Prosthodontics, Vol. 8, No. 2, 1995, pp. 105-116.

[12] D. C. Jagger, A. Harrison and K. D. Jandt, "The Reinforcement of Dentures," Journal of Oral Rehabilitation, Vol. 26, No. 3, 1999, pp. 185-194. doi:10.1046/j.1365-2842.1999.00375.x

[13] R. A. Rodford, "Further Development and Evaluation of High-Impact-Strength Denture Base Materials," Journal of Dentistry, Vol. 18, No. 3, 1990, pp. 151-157. doi:10.1016/0300-5712(90)90056-K

[14] G. D. Stafford, J. F. Bates, R. Huggett and R. Handley, "A Review of the Properties of Some Denture Base Polymers," Journal of Dentistry, Vol. 8, No. 4, 1980, pp. 292306. doi:10.1016/0300-5712(80)90043-3

[15] Y. Katsumata, S. Hojo, N. Hamano, T. Watanabe, H. Yamaguchi, H. Okada, T. Teranaka and S. Ino, "Bonding Strength of Autopolymerizing Resin to Nylon Denture Base Polymer," Dental Materials Journal, Vol. 8, No. 4, 2009, pp. 2409-2418. doi:10.4012/dmj.28.409

[16] M. Vojdani and A. A. R. Khaledi, "Transverse Strength of Reinforced Denture Base Resin with Metal Wire and E-Glass Fibers," Journal of Dentistry, Vol. 3, No. 4, 2006, pp. 167-172.

[17] S. B. Sehajpal and V. K. Sood, "Effect of Fillers on Some Physical Properties of Acrylic Resin," The Journal of Prosthetic Dentistry, Vol. 61, No. 6, 1989, pp. 746-751. doi:10.1016/S0022-3913(89)80055-1

[18] T. Nejatian, A. Johnson and R. Van Noort, "Reinforcement of Denture Base Resin," Advances in Science and Technology, Vol. 49, 2006, pp. 124-129. doi:10.4028/www.scientific.net/AST.49.124

[19] P. K. Vallittu and V. P. Lassila, "Effect of Metal Streng- 
thener'S Surface Roughness on Fracture Resistance of Acrylic Denture Base Material," Journal of Oral Rehabilitation, Vol. 19, No. 4, 1992, pp. 385-391. doi:10.1111/j.1365-2842.1992.tb01580.x

[20] S. K. Garoushi, L. V. J. Lassila and P. K. Vallittu, "Short Fiber Reinforced Composite: The Effect of Fiber Length and Volume Fraction," Journal of Contemporary Dental Practice, Vol. 7, No. 5, 2006, pp. 10-17.

[21] H. D. Stipho, "Effect of Glass Fibre Reinforcement on Some Mechanical Properties of Autopolymerizing Polymethyl Methacrylate," Journal of Prosthetic Dentistry, Vol. 79, No. 5, 1998, pp. 580-584. doi:10.1016/S0022-3913(98)70180-5

[22] I. H. Tacir, J. D. Kama, M. Zortuk and S. Eskimez, "Flexural Properties of Glass Fibre Reinforced Acrylic Resin Polymers," Australian Dental Journal, Vol. 51, No. 1, 2006, pp. 52-56. doi:10.1111/j.1834-7819.2006.tb00401.x

[23] P. K. Vallittu, "Strength and Interfacial Adhesion," In: P. K. Vallittu, Ed., The Second International Symposium of Fibre Reinforced Plastics in Dentistry, University of Türkü, Türkü, 2002, pp. 2-28.

[24] J. De Boer, S. G. Vermilyea and R. E. Brady, "The Effect of Carbon Fiber Orientation on the Fatigue Resistance and Bending Properties of Two Denture Resins," The Journal of Prosthetic Dentistry, Vol. 51, No. 1, 1984, pp. 119-121. doi:10.1016/S0022-3913(84)80117-1

[25] R. Tandon, S. Gupta and S. K. Agarwal, "Denture Base Materials: From Past to Future," Indian Journal of Dental Sciences, Vol. 2, No. 2, 2010, pp. 33-39.

[26] N. Yazdanie and M. Mahood, "Carbon Fiber Acrylic Resin Composite: An Investigation of Transverse Strength," Journal of Prosthetic Dentistry, Vol. 54, No. 4, 1985, pp. 543-547. doi:10.1016/0022-3913(85)90431-7

[27] A. J. Bowman and T. R. Manley, "The Elimination of Breakages in Upper Dentures by Reinforcement with Carbon Fibre," British Dental Journal, Vol. 156, 1984, pp. 87-89. doi:10.1038/sj.bdj.4805275

[28] İ. Yöndem, M. T. Yücel, F. Aykent and A. N. Öztürk, "Flexural Strength of Denture Base Resin Reinforced with Different Fibers," Journal of the SU Faculty of Dentistry, Vol. 20, No. 1, 2011, pp. 15-20.

[29] S. Y. Chen, W. M. Liang and P. S. Yen, "Reinforcement of Acrylic Denture Base Resin by Incorporation of Various Fibres," Journal of Biomedical Materials Research, Vol. 58, No. 2, 2001, pp. 203-208.

doi:10.1002/1097-4636(2001)58:2<203::AID-JBM1008> 3.0.CO;2-G

[30] J. Ozen, C. Sipahi, A. Caglar and M. Dalkiz, "In Vitro Cytotoxicity of Glass and Carbon Fiber-Reinforced HeatPolymerized Acrylic Resin Denture Base Material," Turkish Journal of Medical Sciences, Vol. 36, No. 2, 2006, pp. 121-126.

[31] K. Ekstrand, I. E. Ruyter and H. Wellendorf, "Carbon Graphite Fiber Reinforced Poly(methyl methacrylate): Properties under Dry and Wet Conditions," Journal of Biomedical Materials Research, Vol. 21, No. 9, 1987, pp. 1065-1080. doi:10.1002/jbm.820210902

[32] T. Kanie, K. Fujii, H. Arikawa and K. Inoue, "Flexural
Properties and Impact Strength of Denture Base Polymer Reinforced with Woven Glass Fibres," Dental Materials, Vol. 16, No. 2, 2000, pp. 150-158. doi:10.1016/S0109-5641(99)00097-4

[33] T. J. D. Kama, M. Zortuk and S. Eskimez, "Flexural Properties of Glass Fibre Reinforced Acrylic Resin Polymers," Australian Dental Journal, Vol. 51, No. 1, 2006, pp. 52-56. doi:10.1111/j.1834-7819.2006.tb00401.x

[34] I. M. Berrong, R. M. Weed and J. M. Young, "Fracture Resistance of Kevlar-Reinforced Poly(methyl methacrylate) Resin: A Preliminary Study," International Journal of Prosthodontics, Vol. 3, No. 4, 1990, pp. 391-395.

[35] A. M. H. Grave, H. D. Chandler and J. F. Wolfaardt, "Denture Base Acrylic Reinforced with High Modulus Fibre," Dental Materials, Vol. 1, No. 5, 1985, pp. 185187. doi:10.1016/S0109-5641(85)80015-4

[36] M. Braden, K. W. M. Davy, S. Parker, N. H. Ladizesky and I. M. Ward, "Denture Base Poly(methyl methacrylate) Reinforced with Ultra-High Modulus Polyethylene Fibres," British Dental Journal, Vol. 164, 1988, pp. 109113. doi: $10.1038 /$ sj.bdj. 4806373

[37] D. L. Gutteridge, "Reinforcement of Poly(methyl methacrylate) with Ultra-High-Modulus Polyethylene Fibre," Journal of Dentistry, Vol. 20, No. 1, 1992, pp. 50-54. doi:10.1016/0300-5712(92)90012-2

[38] N. H. Ladizesky, Y. Y. Cheng and I. M. Ward, "Acrylic Resin Reinforced with Chopped High Performance Poly Ethylene Fibre Properties and Denture Construction," Dental Materials, Vol. 9, No. 2, 1993, pp. 128-135. doi:10.1016/0109-5641(93)90089-9

[39] D. L. Dixon and L. C. Breeding, "The Transverse Strengths of Three Denture Base Resins Reinforced with Polyethylene Fibres," Journal of Prosthetic Dentistry, Vol. 67, No. 3, 1992, pp. 417-419. doi:10.1016/0022-3913(92)90261-8

[40] L. Goguta, L. Marsavina, D. Bratu and F. Topala, "Impact Strength of Acrylic Heat Curing Denture Base Resin Reinforced with E-Glass Fibers," Temporomandibular Joint Disorders, Vol. 56, No. 1, 2006, pp. 88-91.

[41] P. K. Vallittu and K. Ekstrand, "In Vitro Cytotoxicity of Fibre-Polymethyl Methacrylate Composite Used in Dentures," Journal of Oral Rehabilitation, Vol. 26, No. 8, 1999, pp. 666-671. doi:10.1046/j.1365-2842.1999.00431.x

[42] G. S. Solnit, "The Effect of Methyl Methacrylate Reinforcement with Silane-Treated and Untreated Glass Fibres," Journal of Prosthetic Dentistry, Vol. 66, No. 3, 1991, pp. 310-314. doi:10.1016/0022-3913(91)90255-U

[43] P. K. Vallittu, "The Effect of Void Space and Polymerization Time on Transverse Strength of Acrylic-Glass Fibre Composite," Journal of Oral Rehabilitation, Vol. 22, No. 4, 1995, pp. 257-261. doi:10.1111/j.1365-2842.1995.tb00083.x

[44] K. K. Narva, P. K. Vallittu, Helenius and A. Yli-Urpo, "Clinical Survey of Acrylic Resin Removable Denture Repairs with Glass-Fibre Reinforcement," International Journal of Prosthodontics, Vol. 3, 2001, pp. 219-224.

[45] O. Karacaer, T. N. Polat, A. Tezvergil, L. V. Lassila and 
P. K. Vallittu, "The Effect of Length and Concentration of Glass Fibres on the Mechanical Properties of an Injection- and a Compression-Molded Denture Base Polymer," Journal of Prosthetic Dentistry, Vol. 90, No. 4, 2003, pp. 385-393. doi:10.1016/S0022-3913(03)00518-3

[46] A. K. Cizdemir and T. N. Polat, "The Effect of Glass Fibre Distribution on the Transverse Strength and Surface Smoothness of Two Denture Resins," Dental Materials Journal, Vol. 22, No. 4, 2005, pp. 600-609.

[47] M. Nakamura, H. Takahashi and I. Hayakawa, "Reinforcement of Denture Base Resin with Short-Rod Glass Fiber," Dental Materials Journal, Vol. 26, No. 5, 2007, pp. 733-738. doi:10.4012/dmj.26.733

[48] P. K. Vallittu, "Flexural Properties of Acrylic Resin Polymers Reinforced with Unidirectional and Woven Glass Fibers," Journal of Prosthetic Dentistry, Vol. 81, No. 3, 1999, pp. 318-326. doi:10.1016/S0022-3913(99)70276-3

[49] M. Negrutiu, C. Sinescu, L. Goguta, F. Topala, M. Romînu and A. G. Podoleanu, "Different Types of Fiber Reinforced All Dentures Bases Evaluated by En-Face Optical Coherence Tomography and Numerical Simulation," World Academy of Science, Engineering and Technology, Vol. 53, 2009, pp. 1236-1241.

[50] P. K. Vallittu, "Curing of a Silane Coupling Agent and Its Effect on the Transverse Strength of Autopolymerizing Polymethylmetactylate-Glass Fibre Composite," Journal of Orthopaedic Research, Vol. 24, No. 2, 1997, pp. 124130. doi:10.1046/j.1365-2842.1997.00464.x

[51] P. Hari, A. Kalavathy and H. S. Mohammed, "Effect of Glass Fiber and Silane Treated Glass Fiber Reinforcement on Impact Strength of Maxillary Complete Denture," Annals and Essences of Dentistry, Vol. 3, No. 4, 2011, pp. 7-12. doi:10.5368/aedj.2011.3.4.1.2

[52] Unalan, I. Dikbas and O. Gurbuz, "Transverse Strength of Poly-Methylmethacrylate Reinforced with Different Forms and Concentrations of E-Glass Fibres," OHDMBSC, Vol. 9, No. 3, 2010, pp. 144-147.

[53] D. Vojvodić, D. Komar, Z. Schauperl, A. Čelebić, K. Mehulić and D. Žabarović, "Influence of Different Glass Fiber Reinforcements on Denture Base Polymer Strength (Fiber Reinforcements of Dental Polymer)," Medical
Glass, Vol. 6, No. 2, 2009, pp. 227-234.

[54] D. Galan and E. Lynch, "The Effect of Reinforcing Fibres in Denture Acrylics," Journal of the Irish Dental Association, Vol. 35, 1989, pp. 109-113.

[55] P. K. Vallittu, "Comparison of in Vitro Fatigue Resistance of Acrylic Resin Partial Denture Reinforced with Continuous Glass Fibres or Metal Wire," Journal of Prosthodontics, Vol. 5, No. 2, 1996, pp. 115-121. doi:10.1111/j.1532-849X.1996.tb00285.x

[56] V. M. Miettinen and P. K. Vallittu, "Release of Residual Methyl Methacrylate into Water from Glass Fiber-PolyMethl Methacrylate Composite Used in Dentures," Biomaterials, Vol. 18, No. 2, 1997, pp. 181-185.

[57] H. Yilmaz, C. Aydin, A. Caglar, et al., "The Effect of Glass Fiber Reinforcement on the Residual Monomer Content of Two Denture Base Resins," Quintessence International, Vol. 34, No. 2, 2003, pp. 148-153.

[58] P. K. Vallittu, "Glass Fiber Reinforcement in Repaired Acrylic Resin Removeable Dentures: Preliminary Results of a Clinical Study," Quintessence International, Vol. 28, 1997, pp. 39-44.

[59] P. K. Vallittu, "Dimensional Accuracy and Stability of Poly Methylmethacrylate Reinforced with Metal Wire or with Continuous Glass Fiber," Journal of Prosthodontics, Vol. 75, No. 6, 1996, pp. 617-621. doi:10.1016/S0022-3913(96)90246-2

[60] P. K. Vallittu and K. Narva, "Impact Strength of a Modified Continuous Glass Fiber Poly Methylmethacrylate," International Journal of Prosthodontics, Vol. 10, 1997, pp. 142-148.

[61] V. M. Miettinen and P. K. Vallittu, "Water Sorption and Solubility of Glass Fiber-Reinforced Denture Polymethyl Methacrylate Resin," Journal of Prosthetic Dentistry, Vol. 76, 1996, pp. 531-534.

[62] S. Kondo, Y. Nodasaka and H. Shimokoube, "Bend Strength Properties of Jute Fiber-Reinforced Denture Base Material," IADR/AADR/CADR 87th General Session and Exhibition, Miami, 1-4 April 2009. 